\title{
Prospecting and collecting local groundnut ecotypes in three regions of Burkina Faso
}

\author{
R. Bernard SAWADOGO ${ }^{*}$, K. Marie-Laure GUISSOU ${ }^{1}$, S. NANKONE ${ }^{1}$, E. SAWADOGO \\ /COMPAORE ${ }^{2}$ and M. B. ZAGRE ${ }^{2}$ \\ ${ }^{1}$ Life and Earth Science Laboratory, PO Box: 376 Koudougou, Burkina Faso \\ 2 National Institute for the Environment and Agricultural Research (INERA) Burkina Faso \\ * Corresponding author; E-mail: narson10sawadogo@gmail.com, Tel: 0022676485319
}

Keywords: Prospecting, Ecotypes, local, groundnuts

Publication date 30/04/2020, http://m.elewa.org/Journals/about-japs/

\section{$1 \quad$ ABSTRACT}

This study aimed to understand the social environment of groundnut production in Burkina Faso. The prospecting was carried out in three regions of Burkina Faso, namely the CentralEast, the Central-North, and the Central-West Regions. Data were collected through direct observations and individual interviews using a questionnaire guide. At the end of this study, five (05) local ecotypes were collected which varied according to the ethnic group. These were Mayoro, zampou, dalga in Bissa ethnic group and Balolé, Wobgo in Mooré ethnic group. It appeared that groundnuts are mainly grown by women in small areas and these local ecotypes are disappearing progressively in favour of improved varieties developed by INERA (SH470P, QH243C). Research efforts for an agro-morphological and molecular genetic characterization of local varieties are necessary to facilitate their conservation.

\section{INTRODUCTION}

In Burkina Faso, the main crops in the oilseed sector include peanuts, cottonseeds, sesame seeds, shea nuts, soybeans and cashew nuts. Until 1977, groundnut was the first cash crop in Burkina Faso before cotton (Dyemkouma, 2009). It is cultivated for its seeds, which are used as raw material for the extraction of oil used in cooking and for soap making. In addition, there are several ways of consuming peanuts: either in raw or roasted seeds, or in more or less elaborate forms like edible groundnuts and confectionery such as butter, dough, flour. At the national level, the consumption of groundnut and groundnut past accounts for more than $2.5 \%$ of the average annual household expenditures (INSD, 2005). However, few studies have been carried out on the social phenomenon around groundnut production (taste, colour, duration of production, resistance of the variety to diseases.). In addition, though groundnut genetic diversity is important, there is loss or an abandonment of some local cultivars for highperformance improved varieties. In addition, the heterogeneity of seed types on markets shows the existence of variability within crops cultivated and is not well known. Hence, the reason why this survey was conducted whose general objective is to understand the social environment of groundnut production in three regions of Burkina Faso. The specific objectives include:

- making the inventory of local ecotypes cultivated in these three areas,

- understand the cultivation system and the uses of this product,

- describing the local taxonomy of the cultivated groundnut. 


\section{MATERIALS AND METHODS}

\subsection{Collection areas and sites: The study} was conducted in three regions (03) of Burkina Faso, namely Central-East, Central-West, and Central-North (Figure 1). The first two regions are characterized by an average annual rainfall between 600 and $900 \mathrm{~mm}$. Soils are mostly of tropical ferruginous type, less developed and hydromorphic. An average annual rainfall ranging between 200 and $600 \mathrm{~mm}$ characterizes the Central-North Region. There are there three types of soils: ferruginous soils, Aeolian soils, and clay soils (SP / CPSA, 2002).

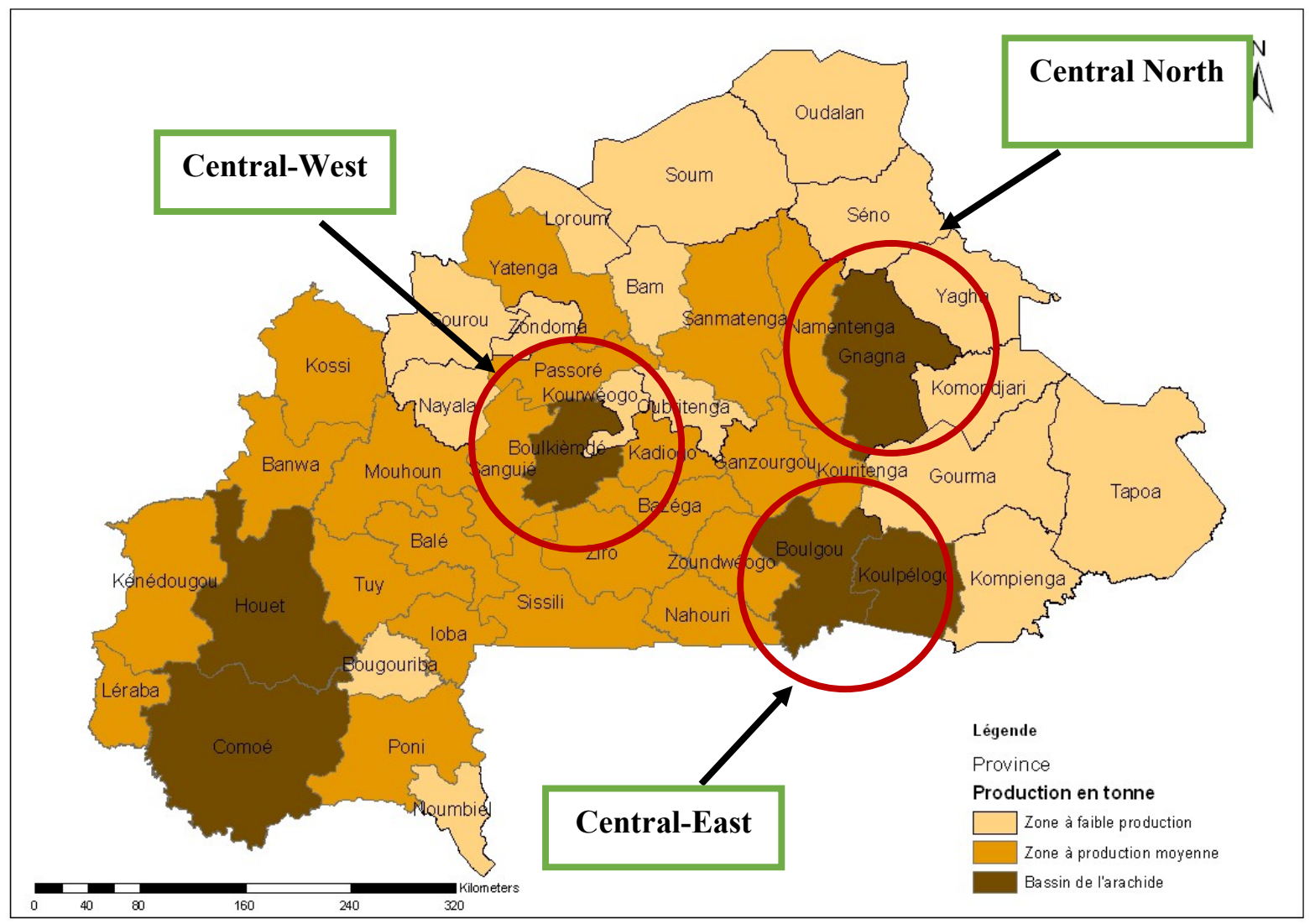

Figure 1: Map showing the various data collection areas (DGESS, 2014)

3.2 Collection method: Six (06) villages are selected based on production basins and peanut production platforms in Burkina Faso. In each of the regions, a random choice of two villages was made and in each of both villages, producers from the platform and outside the platforms were surveyed. Overall, 72 producers were surveyed in these three villages. Data are collected through the various sites during a survey carried out in November 2018, according to the tools and techniques of a participatory research approach based on direct observations, free discussions, group interviews and individual interviews following a questionnaire guide (see annexe). Interviews are conducted in each village with the help of administrative or local authorities (Regional Director of Agriculture, President of producers' Association, agricultural advisers, village chiefs etc.) are involved to facilitate meetings with producers. Notebooks and pencils were used to record as much information as possible, observations and personal ideas made in the field. To transcribe, in the evening, raw notes taken during the day, a larger notebook was quite suitable. Kraft paper bags, which allow air 
circulation and seed ventilation, were used to collect samples of available local groundnut ecotypes. These ecotypes are taken directly from their barns or from their fields. The descriptive parameters used to document the samples collected are those related to the ecotype number, the collector's name, the date of collection, the vernacular and ethnic name,

\section{RESULTS AND DISCUSSION}

\subsection{RESULTS}

4.1.1 Distribution per gender and cultivable area: Major differences are noticed per producer group in terms of number distribution per gender. Producers mainly include women. Indeed, $30.62 \%$ of producers are men while $69.4 \%$ are women (Figure 2). In addition, the surface areas devoted to groundnut production vary between 0.5 ha to 2 the information related to the sampling and the location of the collection site. A collection questionnaire including the identity of the holder, the origin of the material, the uses that are made of it and the constraints of the development of this material was completed at each sampling. Lastly, data obtained were analysed using the sphinx plus2 Software.

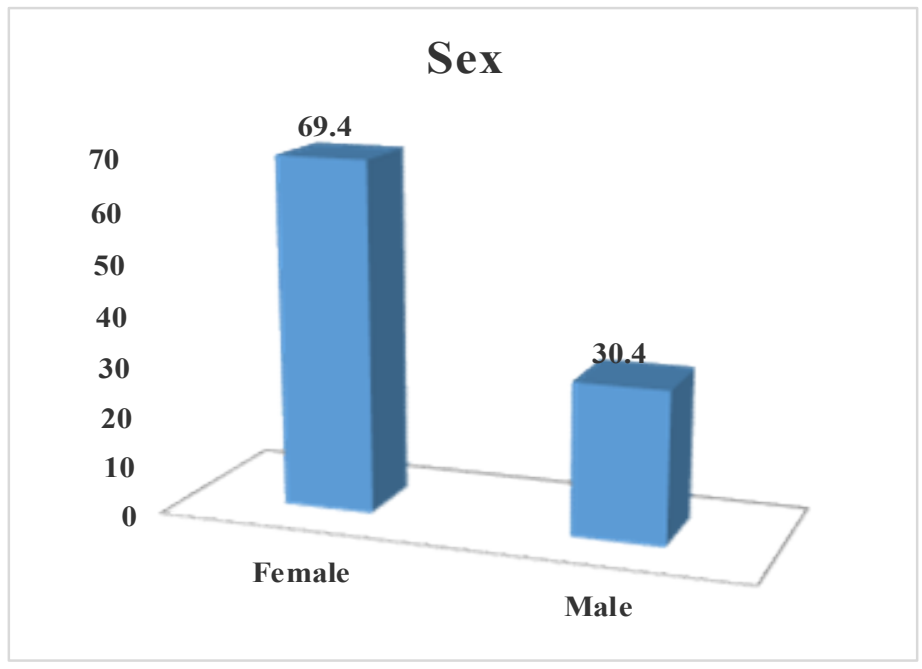

Figure 2: Distribution per gender and type of groundnut

Table 1: Groundnuts area

\begin{tabular}{l|ll}
\hline Area(hectare) & $\begin{array}{l}\text { Number of surveyed } \\
\text { farmers adopted }\end{array}$ & Frequency \\
\hline less than 0.54 & 56 & $77.8 \%$ \\
0.54 to 0.83 & 0 & $0.0 \%$ \\
0.83 to 1.13 & 7 & $9.7 \%$ \\
1.13 to 1.42 & 0 & $0.0 \%$ \\
1.42 to 1.71 & 1 & $1.4 \%$ \\
1.71 to 2.00 & 0 & $0.0 \%$ \\
2.00 and above & 8 & $11.1 \%$
\end{tabular}


Total observations 72 $100 \%$

Minimum $=0.25$, maximum $=2.00$, sum $=51.25$, average $=0.71$, standard deviation $=0.50$

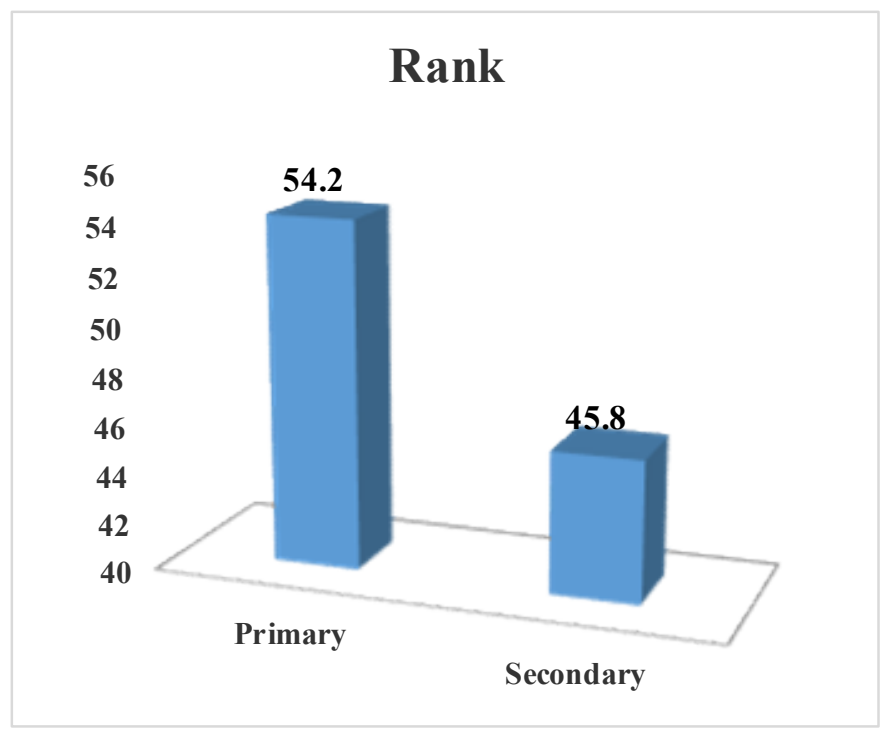

Figure 3: Size of groundnut production among other crops

4.1.2 Educational level: For the whole sample, around $50 \%$ of producers illiterate while $29.2 \%$ have a primary school level, $8.3 \%$ a secondary school level and $12.5 \%$ have received other literacy programs (Koranic school, informal education (Figure 4). From this study, it appears that $77.8 \%$ of illiterate producers are women while men represent $22.2 \%$. $42.85 \%$ of men against $57.14 \%$ of women have a primary school level (Table 2). The number of producers with a secondary school level is low. In fact, $16.7 \%$ of men and $83.3 \%$ of women have secondary level.

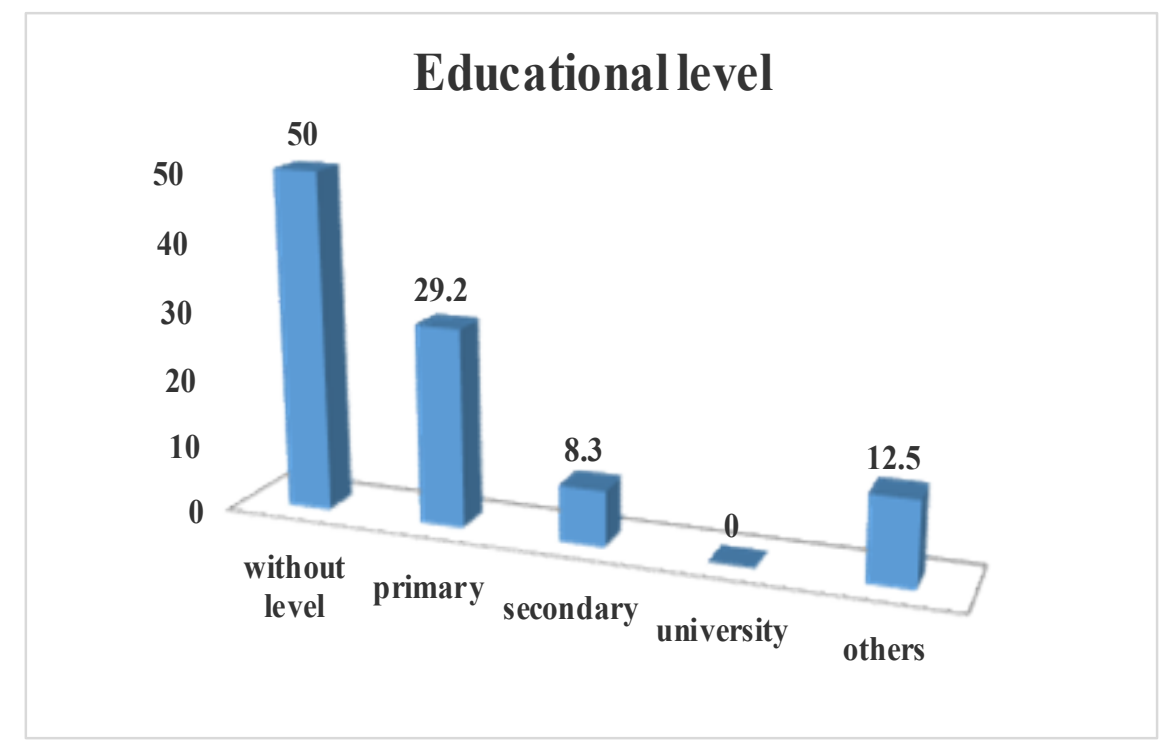

Figure 4: Household education level 
Table 2: Cross-tabulation between the level of education and gender distribution of producers

\begin{tabular}{lllllll}
$\begin{array}{l}\text { Education level } \\
\text { Sex }\end{array}$ & $\begin{array}{l}\text { Without } \\
\text { level }\end{array}$ & Primary & Secondary & University & Other & Total \\
\hline 1.Male & $22.2 \%$ & $42.9 \%$ & $16.7 \%$ & $0.0 \%$ & $44.4 \%$ & $30.6 \%$ \\
2.Female & $77.8 \%$ & $57.1 \%$ & $83.3 \%$ & $0.0 \%$ & $55.6 \%$ & $69.4 \%$ \\
Total & $100 \%$ & $100 \%$ & $100 \%$ & $100 \%$ & $100 \%$ & $100 \%$
\end{tabular}

4.1.3 Groundnut cultivation practices: Groundnut is produced in pure crops by the majority of producers surveyed on sandy-clay soil $(95.8 \%)$ and in a minority on clay soil $(4.2 \%)$. The other cash crops produced by these producers in addition to groundnuts include soy, sesame, and cowpea. With regard to food crops, millet, sorghum and maize are the main crops. Among the producers interviewed, $76.4 \%$ grow groundnuts with fertilizer and $23.6 \%$ without fertilizer (Table 3) and fertilizers used are NPK and organic manure. 59.7\% of producers use chemical fertilizer NPK, most of which are not accessible while $16.7 \%$ use organic manure (Table 4). They practice various production methods, which differ mainly in the number of cultivation operations made on the plot. Indeed, $56.9 \%$ of producers do three weedings, $37.5 \%$ two weedings and $5.6 \%$ one weeding, 23.6\% no answer (Figure 5). The semiflat or $\log$ sowing method and ridging are common cultural practices. Row sowing is most preferred $(83.3 \%)$ followed by flat sowing $(13.9 \%)$ (Figure6). In addition, $45.7 \%$ of producers treat their fields with plant protection products and $54.3 \%$ do not treat them.

Table 3: Use of manure

\begin{tabular}{l|ll}
\hline Manure & $\begin{array}{l}\text { Number of surveyed } \\
\text { farmers adopted }\end{array}$ & Frequency \\
\hline 1.Yes & 55 & $76.4 \%$ \\
2. No & 17 & $24.6 \%$ \\
Total observations & 72 & $100 \%$ \\
& & \\
& & \\
Table 4: Types of manure used & Number of surveyed \\
\hline Types of manure used & farmers adopted & Frequency \\
& 17 & $23.6 \%$ \\
\hline No answer & 43 & $59.7 \%$ \\
Chemical & 12 & $16.7 \%$ \\
Organic & 72 & $100 \%$ \\
Total observations & & \\
&
\end{tabular}




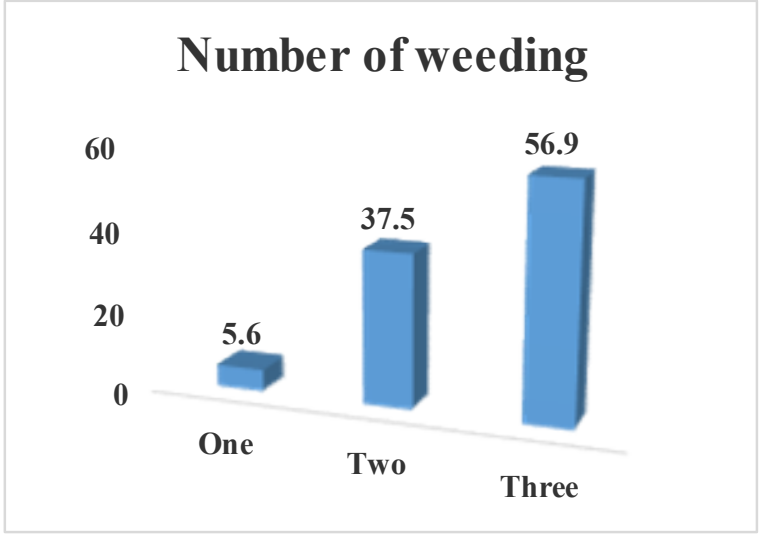

Figure 5: Number of weedings performed

4.1.4 Diseases: With regard to diseases, three main diseases are recorded, namely rosette, rust and leaf spot. In all these regions,

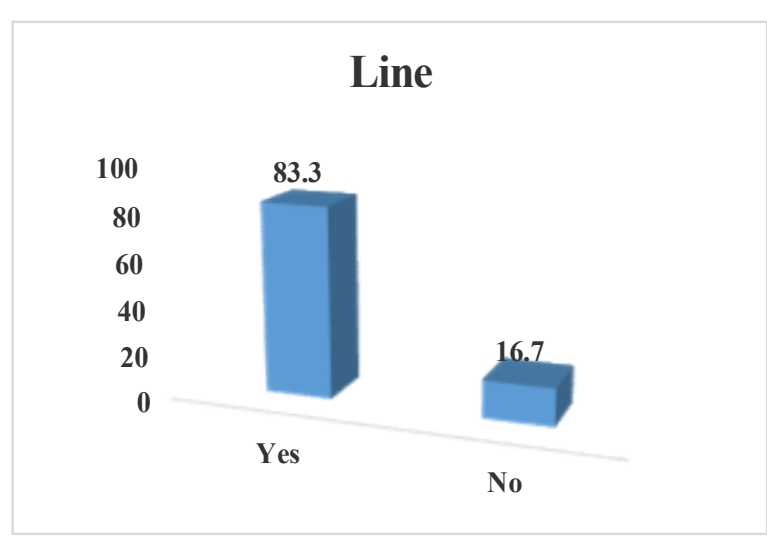

Figure 6: Type of sowing

rosette is the disease recognized by producers with a percentage of $93.1 \%$ followed by rust $6.9 \%$, leaf spot is not known (Figure 3).

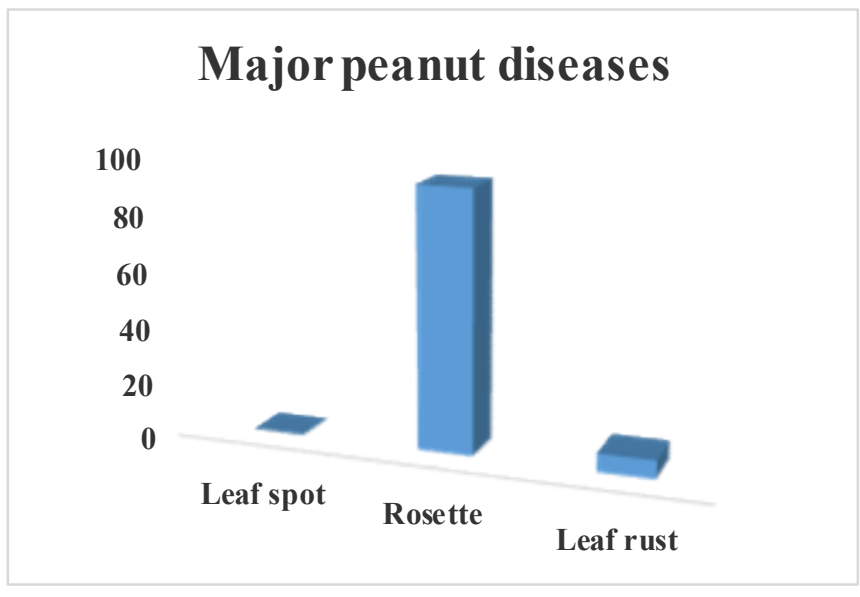

Figure 7: major groundnut disease

4.1.5 Origin of seeds: Producers purchase seeds with research institutes (INERA), which has groundnut platforms in these three regions, or with either by donation or from their production stocks.

4.1.6 Local ecotypes: In these three prospected regions, the name of the groundnut varies according to the ethnic group: Mayoro, konkolo, zampou, dalga in Bissa, Balolé, Sumkam miongou, Wobgo in Mooré, Tchinebatona,
Tchinebania, Abrakatona in Gourounsi. The criteria for the nomenclature of local ecotypes vary according to the seed colour and morphology and the place of cultivation. In these three regions, local ecotypes are about to disappear and be replaced by improved varieties from INERA. In the six villages surveyed, five local ecotypes are listed, namely Mayoro, Zampou, Dalga in the Central-East Region, Wobgo, Balolé in the Central- North Region. 


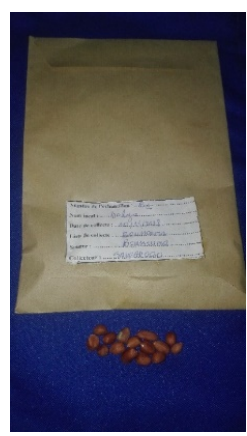

Dalga

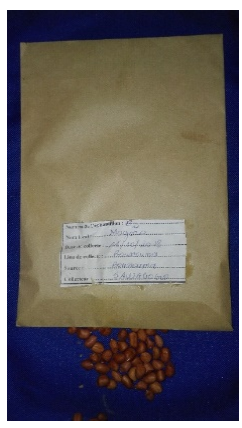

Mayoro

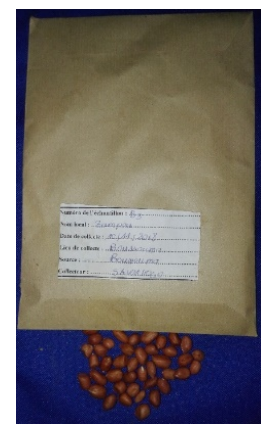

Zampou

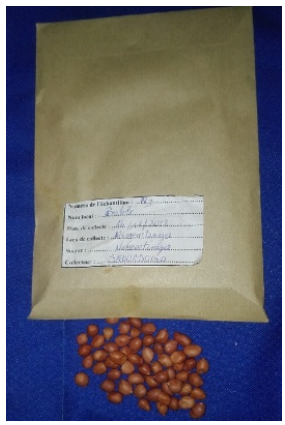

Balolé

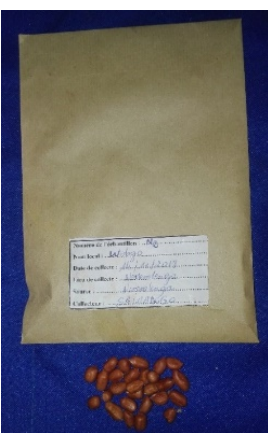

Wobgo

Photo 1: photos of the five local ecotypes collected

Most of producers use improved varieties developed by INERA (SH470P, QH243C). These improved varieties are mainly used by producer's members to the platforms and by the minority of producers who are not members to platforms. Among these five local ecotypes, two ecotypes are the most cultivated, Mayoro and Balolé, in the Central-East and the Central-North regions, respectively. According to all the producers surveyed, they are fairly less demanding in terms of rainfall and soil fertility. They are very appreciated for their short cycle. The factorial analysis of the correspondences shows that there is a relationship between the various ecotypes. Ecotypes tchinebatua and tchinebania are close to the origin of the coordinate system, so their values are almost zero. The Balolé and SH470P ecotypes are similar because they have a negative value. The Mayoro, Konkolo, Dalga ecotypes and the Zampou are symmetrical to the Balolé, Wobgo, Sumkam miougou ecotypes with reference to axis1 and Qh243C is symmetry to SH470C with reference to this axis. These ecotypes are therefore similar side-by-side (Figure 8). 


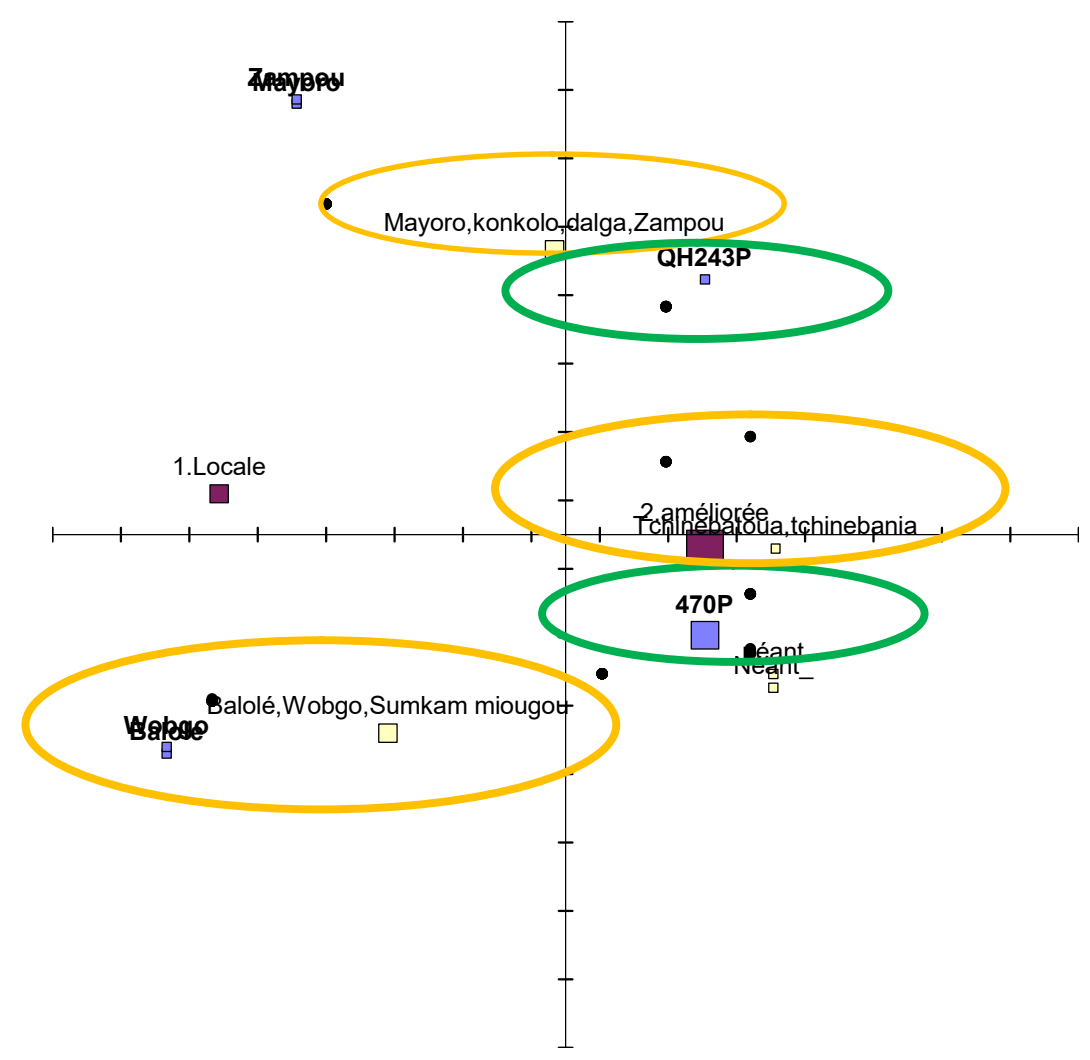

Figure 8: Factorial analysis of ecotype correspondences

\section{DISCUSSION}

Groundnut is mainly grown by women on small surface areas. This is due to social considerations, which confine this activity to a certain category of people, notably women (Nadembèga, 2016). These results corroborate those of Ouoba et al., 2016 who conducted a similar study on earth peas. Producers grow groundnuts on sandy clay soil and rarely on clay soil. This is because fine textured, loose and permeable soils, notably sandy soils, are the most suitable. The production of groundnuts on heavy and clay soils is only recommended if the use of mechanization and timely irrigation are possible (Schilling, 2001). The majority of the producers interviewed use expensive chemical fertilizers used for cotton in their fields. A light annual mineral fertilizer NS-P-K or S-P provides an interesting benefit on the groundnut once again promoted by organic manure to be brought preferably on cereal cultivated in rotation. Indeed, fertilizer use is experiencing a sharp decline due to the deterioration of structures and mechanisms that assist rural producers with loans, subsidies, development companies (Schilling, 2001). More than the half of producers practices three weedings. Weeding is important because the young plant is very sensitive to weed competition; it enables to smoothen and aerate soils and facilitates the root penetration. Most of producers interviewed recognize to having faced attacks of diseases. However, a large number of these producers do not treat seeds or plants over their development process. This may be due to the fact that most of them are illiterate, did not receive any training in groundnut disease, thus do not know the impact of diseases on production. The results of the inventory reveal a variety of groundnut names. They corroborate those of Missihoun et al., 2012 who worked on the traditional management and status of sorghum genetic 
resources. This is because the sociological and cultural attributes of human communities are known as major factors substantially influencing the level of diversity, the conservation and use of crop genetic resources (Sam et al., 2006; Joseph and Antony, 2008) although there is a diversity of local groundnut names at the village and household level. In this study, the number of local ecotypes collected is low. This low intra-specific diversity noticed in villages makes groundnut ecotypes more vulnerable to extinction. Indeed, genetic diversity ensures the sustainability of species (CBD, 2009). The low use or abandonment of local ecotypes could be explained by climate

\section{$5 \quad$ CONCLUSION}

The study showed that groundnuts are mainly grown by women in Burkina. Monoculture or associated cultures are common practices. Early and drought-tolerant ecotypes progressively dominate the variety of crops against late varieties that are demanding in terms of soil fertility and sensitive to drought. Varieties developed by INERA are the most used followed by the local Balolé and Mayoro

\section{REFERENCES}

Adjima O., (2016). Aperçu de la culture du voandzou (Vigna subterranea (L.) Verdcourt) au Burkina Faso : enjeux et perspectives d'amélioration de sa productivité. Int. J. Biol. Chem. Sci. 10(2), 652-665.

Antoine Abel MI., (2012). Gestion traditionnelle et statut des ressources génétiques du sorgho (Sorghum bicolor L. Moench) au Nord-Ouest du Bénin. Int. J. Biol. Chem. Sci. 6(3) : 1003-1018.

CBD., 2009.Quatrième rapport national sur la convention de la diversité biologique. ANDE, Côte d'Ivoire, $146 p$.

Dyemkouma, D., (2009), Rétrospective sur les activités de la SOFIVAR et perspectives, conditions that tend to reduce rainfall. Ecotypes preferred by producers meet the requirements in terms of taste, aesthetics, local market and notably, those related to the adaptation to climate change they enable to assess the scope (Loko et al., 2013; Gbaguidi et al., 2015). Tchinebatoua, Tchinebania, Abrakatoua ecotypes are null because we did not find one of these ecotypes. This is certainly, because producers no longer have these local ecotypes. The other ecotypes are symmetrical because some of them are local ecotypes and others are improved varieties developed by INERA that is why there is a resemblance among them.

ecotypes, respectively. This study also reveals that local ecotypes are endangered. Efforts must be made in terms of research for an agromorphological and molecular genetic characterization of local varieties to facilitate an efficient conservation management and a sustainable use of their improving genetic resources.

INSD, (2005), Résultats de l'enquête burkinabè sur les conditions de vie des ménages, Rapport d'enquête.

Joseph JK, Antony VT. 2008. Ethnobotanical investigations in the genus Momordica L. in the Southern Western Ghats of India. Genet. Resour. Crop Evol., 55 : 713 721.

Loko YL, Dansi A, Agre AP, Akpa N, DossouAminon1 I, Assogba P, Dansi M, Akpagana K, Sanni A. 2013.Perceptions paysannes et impacts des changements climatiques sur la production et la diversité variétale de l'igname dans la zone aride du Nord-Ouest du Bénin. Int. J. Biol. Chem. Sci.,7(2) : 672-695.

Nadembèga S., 2016.Production vivrière et sécurité alimentaire au Burkina Faso : Cas du voandzou dans trois communes 
des trois zones agroécologiques. Diplôme de Master 2, Université Catholique de l'Afrique de l'Ouest, 90p.

Robert SC. (2001). Arachide Données agronomiques de base sur la culture arachidière. Oléagineux, Corps Gras, Lipides. Volume 8, Numéro 3, 230-236.
Sam PM, Mohandas A, Shareef SM, Nair GM. 2006. Biocultural diversity of theendemic 'wild jack fruit tree' on the Malabar coast of South India. Ethnobot

SP/CPSA, (2002), Diagnostic actualisé et stratégie de développement de la filière des oléagineux, Rapport final, 


\section{ANNEX}

\section{Questionnaire for farmer producer}

QUESTION
NUMBER

2
MODE

Investigator's name:

Survey date:

Area / Region :

Province :

Village :

Farmer's name :

Phone/ Contact :

Sex :

Age :

Marital status :

Education level:

Have you received training in Agricultural production?

If yes which ones/one

From which institution did you receive these trainings?

What is your main activity?

What is your secondary@tivity?
ANSWER MODE

1. East center 2. North center 3. Midwest

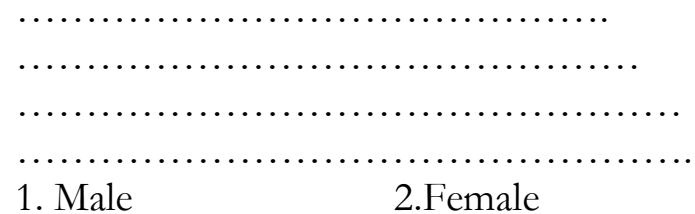

1. Male 2.Female
1. Married
2. Single
3. Divorced
4. widower/widow

1. Without level

2. Primary level

3. Secondary level

4. University
2. Nos

$\ldots \ldots \ldots \ldots \ldots \ldots \ldots \ldots \ldots \ldots \ldots \ldots \ldots \ldots \ldots$

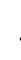

1. Agriculture

6. Others

2. Breeding

3. Fishing

4. Trade

5. Craft

1. Agriculture

2. Breeding

3. Fishing

4. Trade

5. Crafts 
other

How many years have you been 1 . Less than 5 years old growing peanuts?

On average what is the area of your field reserved for growing peanuts?

How often do you grow peanuts in

1. One time the year?

How often do you weed the peanut in the year?

How many types of farming do you practice each year?

Which place does peanut growing hold in your agricultural production?

What is the favorable period for sowing groundnuts in your village?

When is the peanut harvest period in your village?

How long after sowing can we have well-formed seeds
On what type of soil do you produce?

1. One time
2. Two times 3. Three times

2. Two times

3. Three times

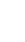
1. May
2. June
3. July

1. September

2. October

3. November

1. Lateritic peanuts

2. Clay

3. Sandy

4. Sandy clay 

the rainy season for groundnut production?

Why? your peanut preferences for production.

\section{Big seed 2. Small seed 3. High yield}

4. Oil content 5. Tolerant to insect, weeds, birds and rodents 6.

9. Easy to preserve 10. Other

What types of cropping systems 1.Monoculture are most used in your village for Rotation System the production of groundnut?
2. Associated cultures
3. Gardening
4.
5. Other

If associated crop, with which crop do you associate peanut?

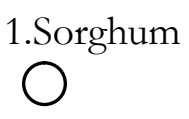

2. Maize

Do you use improved seeds?

1.Yes

2. No

If yes, for how long?

Why do you continue to use improved seeds?

Do you practice any treatment of seeds before sowing?

2. No

Why?

What type of chemical product do you use for treatment?

Do you sow groundnuts online or

1.Yes 
on the $\log$ or online?

What is the spacing used for sowing? peanut?

Why?

Do you apply organic manure to your peanut fields?

Why?

Describe the varieties of peanuts that you used in 2015 .

What is the sown area for produced varieties in 2015? How do you estimate the gained production in 2015 in tons?

What types of varieties did you produce in 2015?

What are the advantages of grown varieties in 2015?

What are the weaknesses of produced varieties in 2015?

What is the origin of varieties that you cultivated in 2015 ?

Describe the varieties of peanuts that you used in 2016. 
What is the sown surface for produced varieties in 2016 ?

How do you estimate the obtained production in 2016 in tons?

What types of varieties did you grow in 2016?

What are the advantages of grown varieties in 2016?

What are the weaknesses of grown varieties in 2016? varieties in 2016?

Describe the varieties of peanuts that you used in 2017 .

What is the sown surface for produced varieties in 2017?

How do you estimate the obtained production in 2017 in tons?

What are the advantages of produced varieties in 2017?

What are the weaknesses of grown varieties in 2017? 
What is] the origin of produced 1. Local varieties in 2017?

For which reasons do you grow peanuts?

List the three most important uses you make of peanuts

Do you use resistant varieties?

Which ones/one?

Why do you use resistant varieties?

What local varieties do you use?

Do you use varieties from abroad or from institutes?

Which ones?

What color of peanut seeds do you prefer?

Why this color?

What is the most used variety in the village?

Why?

What types of improvements are needed for improved varieties?

1. Yes
1. Consumption

2. Improved

\section{Marketing 3. Both}
1. Yes
2. No

2. No

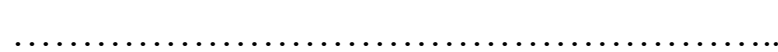

1. White 2. Black 3. Red 4. Pink 5. Maroon $\quad$ 6. Purple
7. Other

$\begin{array}{ll}\text { 1. Number of pods } & \text { 2. Number of seeds in the pod }\end{array}$ 


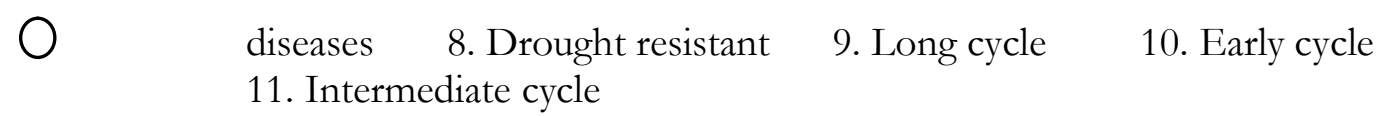

What is the growing cycle of the varieties you use?

What do you think are the main constraints of peanut production in general?

Indicate in priority order the different constraints linked to groundnut production.

What do you consider to be the major problem in groundnut production?

What are the major peanut diseases in your village?

Which causes yield losses?

What are the characteristics of the seeds you want in peanut varieties?

What types of seed improvement are needed for the varieties you are
1. Lack of improved varieties

4. Low yield of varieties

2. High seed price

3. Lack of Materials 6. Diseases 7. Abiotic stress 8. High price of inputs fertilizers and chemicals 9. Problem of land ownership 10. Lack of flow market 11. Absence of agricultural credit 12. Product conservation problem 13. Other

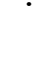

$\ldots$
es ... 
growing?

How important is the size of the 1.Very important peanut seed to you? at all important

How important is peanut 1. Very important resistance to disease? all important

How important is the color of the peanut seed to you?

1. Very important Not at all important
2. Important

2. Important

2. Important
4. Not

3. Not important

3. Not important

4. Not at

3. Not important

Would you adopt a variety from research? 